\title{
Sentinel node mapping for post-endoscopic resection gastric cancer: multicenter retrospective cohort study in Japan
}

\author{
Shuhei Mayanagi ${ }^{1} \cdot$ Naoto Takahashi $^{2} \cdot$ Norio Mitsumori $^{2} \cdot$ Takaaki Arigami $^{3} \cdot$ Shoji Natsugoe $^{3} \cdot$ Yoshihisa Yaguchi $^{4}$. \\ Takeshi Suda $^{5}$. Shinichi Kinami ${ }^{6} \cdot$ Masaki Ohi $^{7}$. Hirofumi Kawakubo ${ }^{1} \cdot$ Yasunori Sato $^{8} \cdot$ Hiroya Takeuchi $^{9}$. \\ Takashi Aikou $^{10}$. Yuko Kitagawa ${ }^{1}$. Japanese Society for Sentinel Node Navigation Surgery
}

Received: 12 November 2019 / Accepted: 27 December 2019 / Published online: 11 January 2020

(c) The Author(s) 2020

\begin{abstract}
Background Standard gastrectomy with systematic lymphadenectomy as an additional surgery after endoscopic resection (ER) causes a deterioration in long-term quality of life. If the sentinel lymph node (SN) basin concept can be applied in post-ER gastric cancer, minimal surgery can be applied without reducing the curability. This retrospective multicenter cohort study aimed to verify the validity of the SN basin concept in post-ER gastric cancer.

Patients and methods Individual data of 132 patients who underwent SN mapping after ER were collected from 8 university hospitals in Japan from 2001 to 2016. Tracers were injected endoscopically in the submucosal layer at four sites around the post-ER scar. We compared the SN basin distribution of post-ER gastric cancer with that of 275 patients with non-ER gastric cancer.

Results Two cases of SN were unidentified, both involving a single tracer (SN detection rate: 98.5\%). Nine cases (6.8\%) of lymph node metastasis were found, of which eight had a metastatic lymph node within the SNs and one had a non-SN metastasis within the SN basin. The diagnostic sensitivity of SN mapping for lymph node metastasis was $88.9 \%$ in post-ER group and $95.7 \%$ in non-ER group $(P=0.490)$; the accuracy was $99.2 \%$ and $99.6 \%(P=0.539)$, respectively. Regarding the SN basin, no significant intergroup differences were found regardless of the primary tumor location.

Conclusions Our findings clarified the feasibility of SN mapping based on the SN basin concept in patients with gastric cancer who previously underwent ER.
\end{abstract}

Keywords Early gastric cancer · Endoscopic mucosal resection · Endoscopic submucosal dissection · Sentinel lymph node

Shuhei Mayanagi

s.mayanagi@keio.jp

1 Department of Surgery, Keio University School of Medicine, 35 Shinanomachi, Shinjuku-ku, Tokyo 160-8582, Japan

2 Department of Surgery, The Jikei University, School of Medicine, Tokyo, Japan

3 Department of Digestive Surgery, Breast and Thyroid Surgery, Kagoshima University Graduate School of Medical and Dental Sciences, Kagoshima, Japan

4 Department of Surgery, National Defense Medical College, Tokorozawa, Japan

5 Department of Gastrointestinal and Pediatric Surgery, Tokyo Medical University, Tokyo, Japan
6 Department of Surgical Oncology, Kanazawa Medical University, Ishikawa, Japan

7 Department of Gastrointestinal and Pediatric Surgery, Division of Reparative Medicine Institute of Life Sciences, Mie University Graduate School of Medicine, Tsu, Mie, Japan

8 Department of Preventive Medicine and Public Health, Biostatistics at Clinical and Translational Research Center, Keio University School of Medicine, Tokyo, Japan

9 Department of Surgery, Hamamatsu University School of Medicine, Hamamatsu, Japan

10 Seiunkai Hospital, Kagoshima, Japan 


\section{Introduction}

The population of patients with gastric cancer is currently aging in Japan. In $2017,45.6 \%$ of patients with newly diagnosed gastric cancer were $>75$ years old [1]. In such a patient background, the popularity of endoscopic resection (ER), including endoscopic mucosal resection (EMR) [2] and endoscopic submucosal dissection (ESD) [3, 4], as a less invasive treatment modality for early gastric cancer has spread dramatically. It is particularly useful for organ preservation and maintaining quality of life (QOL) after treatment. According to the Japanese guidelines for gastric cancer treatment [5], lesions with $<1 \%$ estimated risk of lymph node metastasis are considered equivalent to surgical gastrectomy and defined as absolute-indication lesions. In addition, although the risk of lymph node metastasis is estimated to be $<1 \%$, lesions for which long-term prognostic evidence is poor are defined as expanded-indication lesions. Lesions that were initially defined as expanded-indication have become absolute-indication lesions as verified in a large-scale clinical trial such as JCOG0607 [6]. The indications for ER are gradually expanding. ER curability is determined by two factors: extent of local resection and the possibility of lymph node metastasis. Additional surgical resection, usually laparoscopic standard gastrectomy with systematic lymphadenectomy, is the standard treatment if the risk of lymph node metastasis is estimated from the resected specimen after ER. However, in a few cases, additional surgical resection did not show tumor remnants or lymph node metastasis. Moreover, because of standard gastrectomy and systematic lymphadenectomy, it becomes a serious problem that causes a decrease in long-term QOL, including postoperative weight loss, especially in elderly patients.

The SN concept supports the theory that sentinel lymph nodes (SNs) receive lymph flow directly from the tumor and experience the first lymph node metastasis. If no lymph node metastasis is found in the SNs, it is judged that there is no metastasis in other lymph nodes. Surgery using the $\mathrm{SN}$ concept is actively attempted as a safer attempt at minimally invasive surgery. In breast cancer and malignant melanoma, individualized surgery, including SN biopsy, has been standardized [7, 8], and the application to clinical practice for various cancers has also been reported [9-12]. In early gastric cancer, Miwa et al. proposed the concept of SN basin dissection in which SN basins contained true metastatic nodes even in patients with a false-negative SN biopsy [13]. A prospective multicenter clinical trial was conducted by our study group, the Japanese Society for Sentinel Node Navigation Surgery (SNNS), in order to verify the validity of SN mapping for gastric cancer [14]. This prospective study determined that $\mathrm{SN}$ basin dissection, which was considered a minimally focused lymphadenectomy, was acceptable without compromising the curability of cT1 N0 gastric cancer with no previous treatment. If the $\mathrm{SN}$ basin concept can be applied even in post-ER lesions, it may be possible to conduct minimal surgery that preserves postoperative QOL without degrading the curability. A detection of lymph node metastasis by SN biopsy followed by SN basin resection as an additional surgery for post-ER gastric cancer is a highly attractive treatment strategy. However, the lymph flow around the primary lesion may change by ER, and this has not been verified in previous prospective study. Regarding the SN of post-ER gastric cancer, only two single-center retrospective studies had high $\mathrm{SN}$ detection rates and diagnostic accuracies for lymph node metastasis $[15,16]$. The $\mathrm{SN}$ basin reportedly did not differ from the control group without ER. However, single-center studies include small sample sizes, and inadequate evidence supports its validity. Therefore, this multicenter retrospective cohort study aimed to verify the feasibility of the $\mathrm{SN}$ basin concept in post-ER gastric cancer.

\section{Patients and methods}

\section{Patients}

From February 2001 to March 2016, the individual data of patients who underwent SN mapping after ER were collected for this retrospective study from the following eight university hospitals: Keio University, Jikei University, Kagoshima University, National Defense Medical College, Tokyo Medical University, Mie University, and Kanazawa Medical University. The conditions of the facilities for participating in this study were as follows: (1) belonging to the Japanese society of SNNS, (2) having capabilities of providing the dual-tracer method, (3) high volume center for SNNS, (4) experienced surgical staffs, and (5) special functioning hospitals approved by the Ministry of Health, Labour and Welfare in Japan. The Japanese Society for SNNS multicenter prospective trial data [14] were used as a historical control with $\mathrm{pT} 1,<4 \mathrm{~cm}$ in diameter, and no previous treatment. The patient data were collected after approval was obtained from the institutional review board of each hospital. (Approval numbers: Keio University 20170353, Jikei University 30-314(9335), Kagoshima University 180081, National Defense Medical College 2958, Tokyo Medical University T2018-0020, Mie University H2019015 and Kanazawa Medical University 1315).

\section{SN mapping procedure}

We identified SNs using either the radioisotope (RI) 99m Tc tin colloid or dye [indocyanine green (ICG), patent blue, or indigo carmine], or a combination of the tracers that were 
used in a previous clinical trial [14]. Briefly, $2.0 \mathrm{ml}$ of RI (99 $\mathrm{m} \mathrm{Tc}$ tin colloid; $0.5 \mathrm{ml} \times 4$ points; $150 \mathrm{MBq} ; 0.3 \mathrm{mCi}$ at the time of surgery) was injected endoscopically in the submucosal layer at four sites around the post-ER scar the day before surgery. It was difficult to inject the tracers in the scar tissue after ER. Therefore, the tracers were properly injected in the submucosal layer around the scar at a distance of approximately $2 \mathrm{~cm}$ from the center of the ER scar. At the start of the surgery, the gastrocolic ligament was divided to visualize every direction of lymph flow from the stomach. Then, $0.5 \mathrm{ml}$ of each of the dye $(0.5 \%$ ICG, patent blue or indigo carmine) was injected intraoperatively on four spots of the submucosa around the ER scar with the same procedure as the RI injection. Immediately after the dye injection, the lymphatic vessels and lymph nodes that were dyed blue or fluoresced under infrared observation were identified, and the lymph nodes stained up to $15 \mathrm{~min}$ after dye injection were regarded as SNs. At the same time, radioactive SNs were identified using a portable gamma probe. The lymph nodes with a radioactivity of $>10$ times the background were also defined as SNs. In non-ER gastric cancer patients, a historical control, $\mathrm{SN}$ detection was performed in the same way using both RI 99m Tc and dye combination in all cases.

Gastric lymphatic basins were classified into five directions along the main gastric feeding arteries as follows: left gastric artery (lymph node stations 1, 3a, and 7), right gastric artery (lymph node stations 3b, 5, and 8a), left gastroepiploic artery (lymph node stations $4 \mathrm{sa}$ and $4 \mathrm{sb}$ ), right gastroepiploic artery (lymph node stations $4 \mathrm{~d}$ and 6), and posterior gastric artery (lymph node station 11p) [17, 18].

Intraoperative histological examinations using a frozen section of each SN were optional and performed on a caseto-case basis. After SN mapping, we performed a prophylactic lymph node dissection, including at least the lymphatic basin with the SNs.

\section{Statistical analyses}

Baseline clinical and pathological variables were expressed as median and range for continuous variables or frequency and proportion for categorical variables. Statistical analyses were performed using the SPSS version 19 software (IBM Corporation, Armonk, NY, USA). The clinical and pathological variables were analyzed using the Chi-square and Fisher exact tests. Differences were considered statistically significant at $p$ values of $<0.05$.

Table 1 Patients' characteristics

\begin{tabular}{|c|c|c|c|c|c|}
\hline & $\begin{array}{l}\text { ER (+) } \\
N=132\end{array}$ & & $\begin{array}{l}\text { ER (-) } \\
N=275\end{array}$ & & $p$ value \\
\hline Age, years & $68(30-91)$ & & $62(29-87)$ & & $<0.001$ \\
\hline Sex (male/female) & $105 / 27(80 \% / 20 \%)$ & & $183 / 92(67 \% / 33 \%)$ & & 0.007 \\
\hline \multicolumn{6}{|l|}{ Location } \\
\hline (in long axis of the stomach) & & & & & 0.137 \\
\hline Upper & 35 & $27 \%$ & 56 & $20 \%$ & \\
\hline Middle & 59 & $45 \%$ & 114 & $41 \%$ & \\
\hline Lower & 38 & $29 \%$ & 105 & $38 \%$ & \\
\hline (in short axis of the stomach) & & & & & 0.187 \\
\hline Lesser curvature & 51 & $39 \%$ & 112 & $41 \%$ & \\
\hline Greater curvature & 34 & $26 \%$ & 52 & $19 \%$ & \\
\hline Anterior wall & 14 & $11 \%$ & 46 & $17 \%$ & \\
\hline Posterior wall & 26 & $20 \%$ & 65 & $24 \%$ & \\
\hline Unknown & 7 & $4 \%$ & & & \\
\hline$T$ factor & & & & & $<0.001$ \\
\hline pT1a & 28 & $21 \%$ & 146 & $53 \%$ & \\
\hline pT1b1 & 31 & $22 \%$ & 42 & $15 \%$ & \\
\hline$>$ pT1b2 & 68 & $52 \%$ & 87 & $32 \%$ & \\
\hline Unknown & 5 & $5 \%$ & & & \\
\hline Tumor size, mm & $19(5-40)$ & & $25(1-40)$ & & $<0.001$ \\
\hline Duration from ER to SN mapping, days & $66(10-1205)$ & & & & \\
\hline
\end{tabular}

Data are presented as median (range) or frequency and percentage

$E R$ endoscopic resection, $S N$ sentinel lymph node 
Table 2 Surgical findings and factors for additional surgery

\begin{tabular}{lrl}
\hline & ER $(+)$ \\
& $N=132$ \\
\hline Surgical procedure & 60 & $45 \%$ \\
Distal gastrectomy & 4 & $3 \%$ \\
Total gastrectomy & 23 & $17 \%$ \\
Proximal gastrectomy & 10 & $8 \%$ \\
Pylorus-preserving gastrectomy & 14 & $11 \%$ \\
Segmental gastrectomy & 14 & $11 \%$ \\
Local resection & 7 & $5 \%$ \\
SN basin resection only & & \\
Lymphadenectomy & 32 & $24 \%$ \\
SN basin (D0) & 17 & $13 \%$ \\
D1 & 65 & $49 \%$ \\
D1+ & 18 & $14 \%$ \\
D2 & & \\
Factor for additional surgery & 68 & $52 \%$ \\
T factor (deeper than SM2) & 11 & $8 \%$ \\
Beyond the expanded criteria for ER [size, ulcerative & & \\
findings (UL) and histological type] & 63 & $48 \%$ \\
Horizontal margin/vertical margin of local recurrence & 67 & $36 \%$ \\
Lymphovascular infiltration & & \\
Other & 1 & $1 \%$ \\
$\quad$ Non-en bloc resection & 2 & $2 \%$ \\
$\quad$ Perforation & & \\
\hline
\end{tabular}

$E R$ endoscopic resection

\section{Results}

The clinicopathological parameter values of the 132 patients who underwent SN mapping after ER are shown in Table 1. The median age of the patients was 68 years, and $80 \%$ of the patients in the ER group were male. In the ER group, the primary tumor was located in the upper, middle, and lower parts of the stomach in $27 \%, 45 \%$, and $29 \%$ of the patients, respectively, with no statistically significant difference from the non-ER group ( $p=0.137)$. After ER, the pathological $T$ factor was deeper than T1b2 (SM2) in approximately 52\%

\section{Lymph node metastasis case}

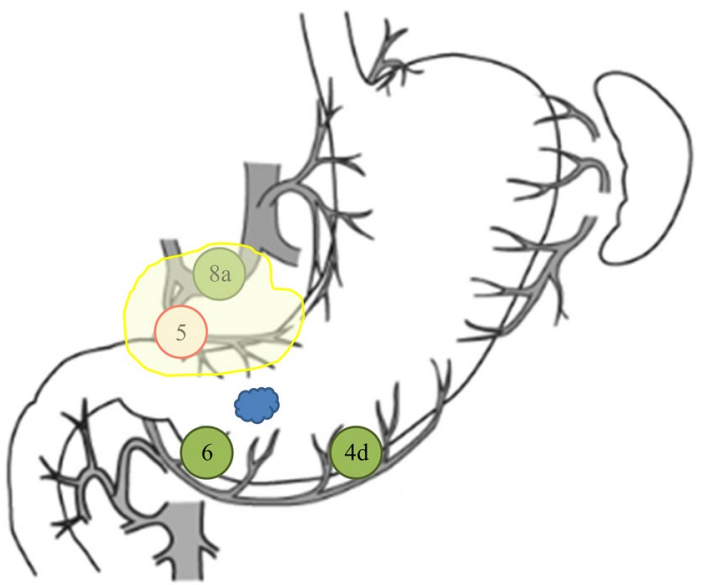

Fig. 1 A false-negative case (L Post tub1 T1a-M ly0 v0 post-EMR, ICG only). The sentinel lymph nodes (SNs) were detected in lymph node stations $4 \mathrm{~d}, 6$, and 8 . The metastatic lymph node was postoperatively diagnosed in lymph node station 5 . Non-SN metastasis was included within the right gastric arterial basin. The yellow area indicates the right gastric arterial basin detected as one of the $\mathrm{SN}$ basins

of all the patients. The median tumor diameter was $19 \mathrm{~mm}$, which was smaller than that in the non-ER group. The interval from ER to SN mapping was 66 days. The surgical procedures and reasons for the additional surgery are listed in Table 2. Of all the patients, 52\% underwent minimalized surgery, whereas $5 \%$ underwent only $\mathrm{SN}$ basin resection. Pathological $T$ factor and resection margin/local recurrence occurred in approximately $50 \%$ of the patients, while lymphovascular infiltration affected approximately one-third of all the patients.

Regarding the tracer for SN mapping, 68 patients $(52 \%)$ received dual tracers, including both $\mathrm{RI}$ and dye, while 63 patients $(48 \%)$ received a single tracer [dye only in $49(37 \%)$ and RI only in $15(11 \%)$ ]. Two cases of SN were unidentified, both involving a single tracer (either RI or dye only). The primary tumor in both cases with an unidentified SN was a T1b-SM2 lesion that had been subjected to ESD. The patient who received dye only was obese and experienced

Table 3 Results of SN mapping

\begin{tabular}{|c|c|c|c|c|c|}
\hline & $\mathrm{ER}(+)$ & & $\mathrm{ER}(-)$ & & $p$ value \\
\hline Overall lymph node metastasis rate, $\%$ & 6.8 & $(9 / 132)$ & 8.4 & $(23 / 275)$ & 0.588 \\
\hline Number of SN & $5(1-22)$ & & $5(1-24)$ & & 0.820 \\
\hline Detection rate, $\%$ & 98.5 & $(130 / 132)$ & 100.0 & $(275 / 275)$ & 0.105 \\
\hline Sensitivity, \% & 88.9 & $(8 / 9)$ & 95.7 & $(22 / 23)$ & 0.490 \\
\hline Negative predictive value, $\%$ & 99.2 & $(121 / 122)$ & 99.6 & $(252 / 253)$ & 0.545 \\
\hline Diagnostic accuracy, \% & 99.2 & $(129 / 130)$ & 99.6 & $(274 / 275)$ & 0.539 \\
\hline
\end{tabular}

Data are presented as median (range) or frequency and percentage

$E R$ endoscopic resection 
Fig. 2 Distribution of the SN stations by a primary tumor location in the long axis of the stomach: a upper third. b Middle third. SNs were detected in station $3 \mathrm{a}$ in $>70 \%$ of the cases with a primary tumor at the upper or middle third. Station $4 \mathrm{~d}$ was also detected as the $\mathrm{SN}$ in around half of the cases with a tumor in the middle third. c Lower third. Stations $4 \mathrm{~d}$ and 6 were detected as the SNs in $61 \%$ and $58 \%$ of the cases, respectively. The red node indicates the stations detected as SNs in $>50 \%$ of the cases. The green node indicates the stations detected as SNs between 10 and 50\% of the cases. The blue node indicates the stations detected as SNs in $<5 \%$

a perforation during ESD. Therefore, the $\mathrm{SN}$ detection rate was $98.5 \%(130 / 132$; Table 3$)$.

Of the nine cases $(6.8 \%)$ of $\mathrm{LN}$ metastasis, eight had metastatic LN within SNs and one had non-SN metastasis within a SN basin. In the single false-negative case, the primary tumor with pT1a that was located at the posterior wall of the lower third of the stomach was resected using EMR. SN mapping was performed using a single tracer with ICG at 6 months after the EMR. Seven SNs were detected in lymph node stations $4 \mathrm{~d}, 6$, and 8 ; however, the metastatic lymph node was postoperatively diagnosed in station 5 (Fig. 1). Therefore, a non-SN metastasis was included within the right gastric arterial basin detected as the sentinel basin. For the patients with gastric cancer who had undergone ER, the diagnostic sensitivity and accuracy of SN mapping for lymph node metastasis were $88.9 \%$ and $99.2 \%$, respectively (Table 3).

Finally, the SN distribution by primary tumor location is shown in Figs. 2 and 3. SNs were detected in station 3a in $>70 \%$ of cases with a primary tumor in the upper or middle third. Station $4 \mathrm{~d}$ was also detected as the $\mathrm{SN}$ in approximately $50 \%$ of the cases with a tumor located at the middle third. On the other hand, in the cases with a tumor located in the lower third, the SNs in stations $4 \mathrm{~d}$ and 6 were detected in $61 \%$ and $58 \%$ of the cases, respectively. (Fig. 2) By the tumor location in the short axis of the stomach, SNs were detected in station 3a in $78 \%$ of cases with a primary tumor located in the lesser curvature, or in station $4 \mathrm{~d}$ in $76 \%$ of cases with a primary tumor located in the greater curvature. In the cases with a tumor located in the anterior wall, the SNs in stations $3 \mathrm{a}$ and $4 \mathrm{~d}$ were detected in $64 \%$ of the cases, respectively. Station 3 a was also detected as the $\mathrm{SN}$ in $65 \%$ of the cases with a tumor located in the posterior wall (Fig. 3). Regarding the SN basin, no statistically significant intergroup difference was found regardless of primary tumor location based on both the long axis and the short axis of the stomach (Table 4). a Distribution of SN station

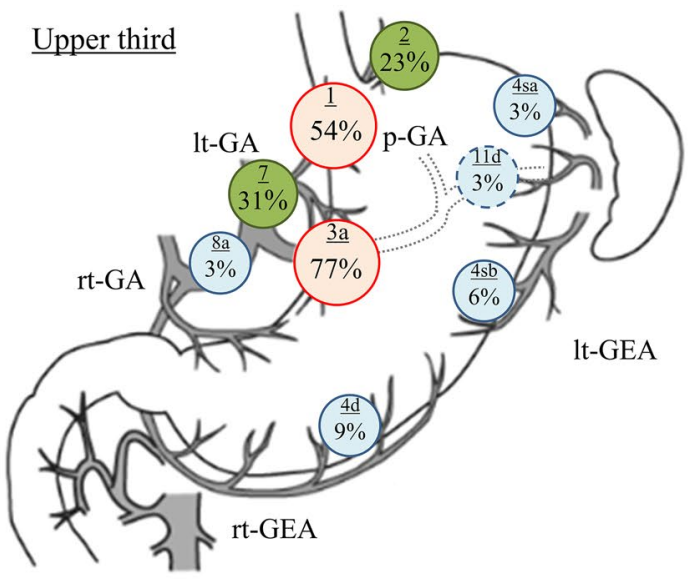

b Distribution of SN station

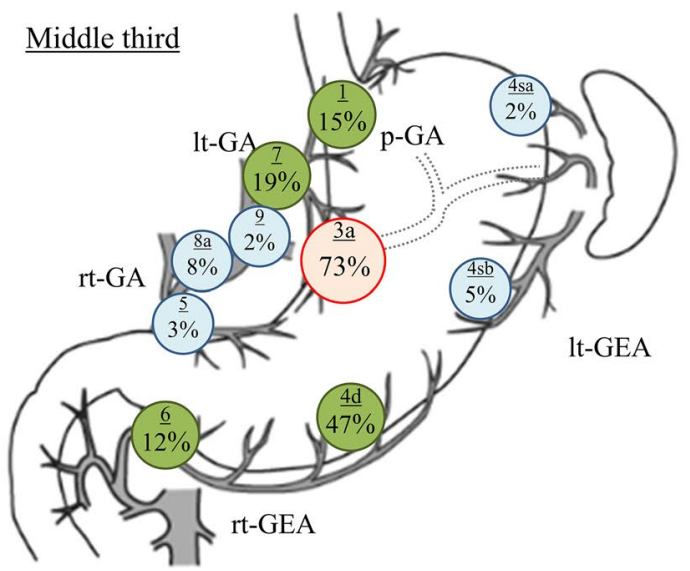

c Distribution of SN station

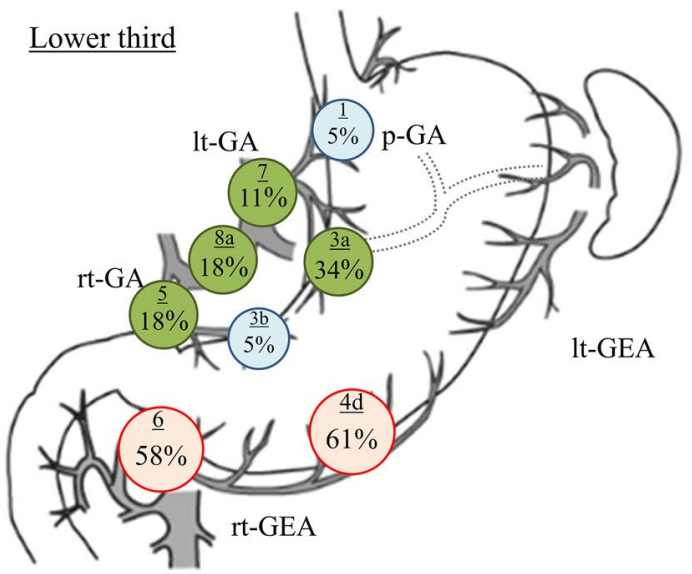

\section{Discussion}

The present study demonstrated that SN mapping for patients with gastric cancer after ER showed high detection and diagnostic accuracy rates like in those without previous 


\section{a Distribution of SN station}

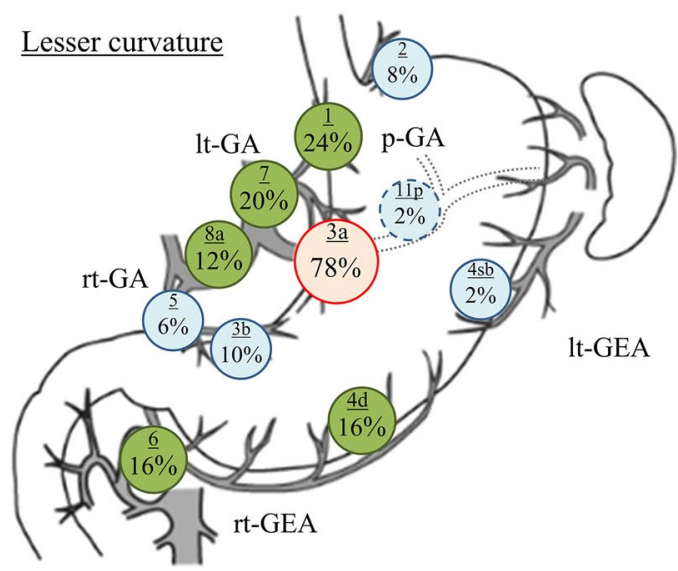

c Distribution of SN station

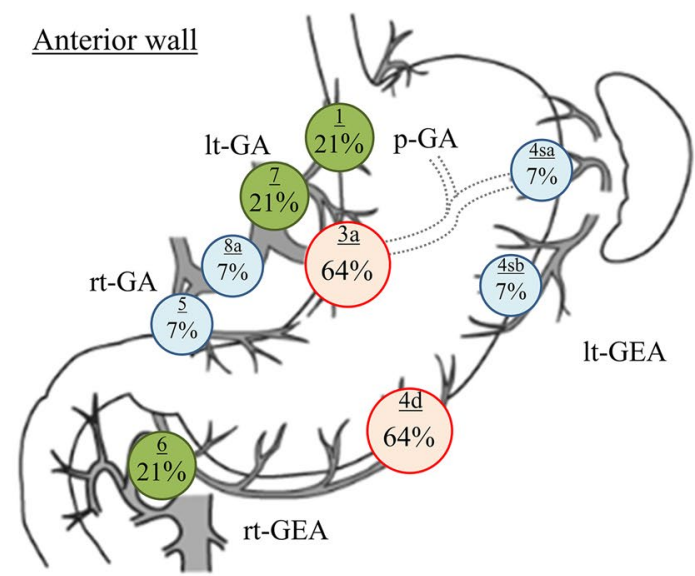

Fig. 3 Distribution of the SN stations by a primary tumor location in the short axis of the stomach: a Lesser curvature. SNs were detected in station $3 \mathrm{a}$ in $78 \%$ of cases with a primary tumor located in the lesser curvature. b Greater curvature. SNs were detected in station $4 \mathrm{~d}$ in $76 \%$ of cases with a primary tumor located in the greater curvature. c Anterior wall. The SNs in stations 3a and 4d were detected in $64 \%$

treatment, although one false-negative case had a non-SN metastasis in the SN basin. Moreover, no significant difference in $\mathrm{SN}$ basin distribution was found between the patients after ER and those without previous treatment regardless of the primary tumor location. To the best of our knowledge, this is the first multicenter study with a large cohort to report the feasibility of SN mapping.

The SN detection rate of $98 \%$ in the ER group was comparable with that in the non-ER group. When a tracer is injected after ER, the influences of ER, including scarring and ulceration, are concerns. The tracer injection and SN detection should be performed by a physician familiar with SN mapping for gastric cancer. In our study, we had two b Distribution of SN station

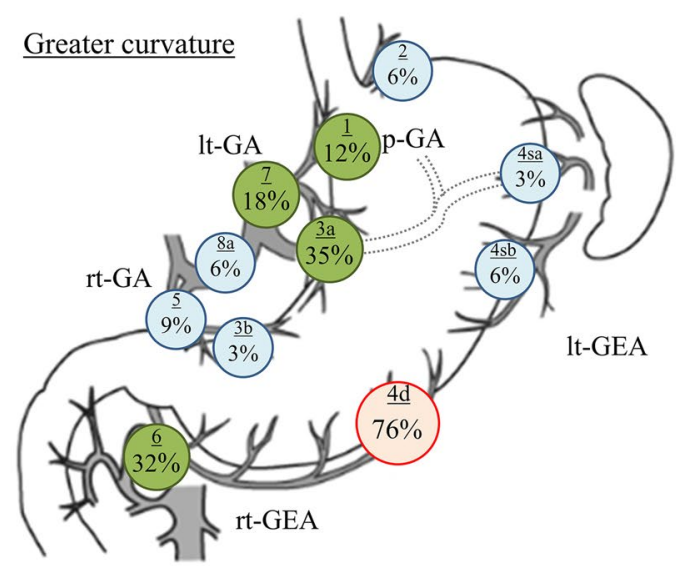

d Distribution of SN station

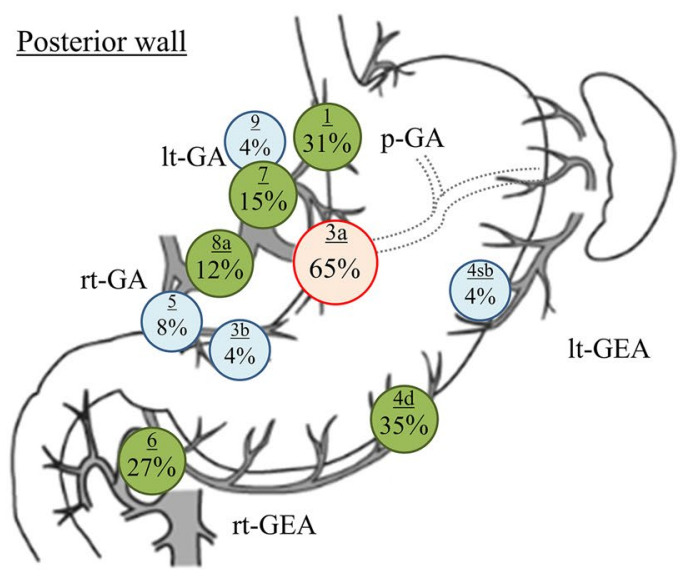

of the cases, respectively. d Posterior wall. Station 3a was detected as the $\mathrm{SN}$ in $65 \%$ of the cases with a tumor located at posterior wall. The red node indicates the stations detected as SNs in $>50 \%$ of the cases. The green node indicates the stations detected as SNs between 10 and $50 \%$ of the cases. The blue node indicates the stations detected as $\mathrm{SNs}$ in $<5 \%$

cases of undetected SN among the patients who underwent the single-tracer method, one with RI and the other with ICG. The SN may be difficult to identify using a single tracer with dye alone in obese patients. As we reported previously, the dual-tracer method is considered the most reliable for identifying the SN in gastric cancer $[19,20]$. When considering the tracer type used, a meta-analysis revealed that the $\mathrm{SN}$ detection rates in the dye, RI, and dual-tracer groups were $92.1 \%, 92.1 \%$, and $94.0 \%$, respectively [21]. In addition, the sensitivity, negative predictive value, and accuracy in the dual subgroup were higher than those in the dye and RI groups. Meanwhile, in this study, the SNs could not be identified in a patient in whom perforation occurred during 
Table 4 Distribution of SN basin

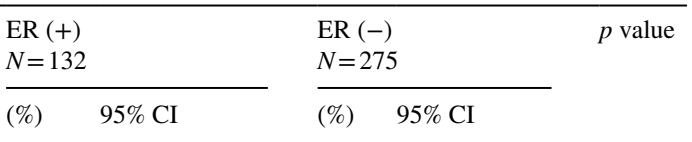

Tumor location based on the long axis of the stomach

Upper

$\begin{array}{clllll}\text { 1-GA } & 100.0 & (100.0 \text { to } 100.0) & 94.2 & (87.7 \text { to } 100.8) & 0.216 \\ \text { 1-GEA } & 8.8 & (-1.2 \text { to } 18.9) & 13.5 & (3.9 \text { to } 23.1) & 0.770 \\ \text { r-GA } & 2.9 & (-3.0 \text { to } 8.9) & 3.8 & (-1.6 \text { to } 9.3) & 1.000 \\ \text { r-GEA } & 11.8 & (0.4 \text { to } 23.2) & 11.5 & (2.6 \text { to } 20.5) & 1.000 \\ \text { p-GA } & 0 & (0.0 \text { to } 0.0) & 3.8 & (-1.6 \text { to } 9.3) & 0.363 \\ \text { Others } & 23.5 & (9.0 \text { to } 38.6) & 13.5 & (3.9 \text { to } 23.1) & 0.361 \\ \text { Middle } & & & & & \\ \text { 1-GA } & 86.4 & (77.4 \text { to } 95.4) & 82.3 & (75.7 \text { to } 89.0) & 0.628 \\ \text { 1-GEA } & 6.8 & (0.2 \text { to } 13.4) & 8.5 & (3.6 \text { to } 13.3) & 0.941 \\ \text { r-GA } & 18.6 & (8.4 \text { to } 28.9) & 9.2 & (4.2 \text { to } 14.3) & 0.117 \\ \text { r-GEA } & 55.9 & (42.9 \text { to } 69.0) & 54.6 & (45.9 \text { to } 63.3) & 0.993 \\ \text { p-GA } & 1.7 & (-1.7 \text { to } 5.1) & 0.8 & (-0.8 \text { to } 2.3) & 1.000 \\ \text { Others } & 1.7 & (-1.7 \text { to } 5.1) & 3.8 & (0.5 \text { to } 7.2) & 0.782 \\ \text { Lower } & & & & & \\ \text { 1-GA } & 51.4 & (34.6 \text { to } 68.2) & 66.7 & (56.9 \text { to } 76.4) & 0.156 \\ \text { l-GEA } & 0.0 & (0.0 \text { to } 0.0) & 1.1 & (-1.13 .2) & 0.715 \\ \text { r-GA } & 45.9 & (29.1 \text { to } 62.8) & 34.4 & (24.6 \text { to } 44.2) & 0.306 \\ \text { r-GEA } & 89.2 & (78.7 \text { to } 99.7) & 79.6 & (71.2 \text { to } 87.9) & 0.296 \\ \text { p-GA } & 0.0 & (0.0 \text { to } 0.0) & 0.0 & (0.0 \text { to } 0.0) & \text { NA } \\ \text { Others } & 0.0 & (0.0 \text { to } 0.0) & 4.3 & (0.1 \text { to } 8.5) & 0.257\end{array}$

Tumor location based on the short axis of the stomach

\begin{tabular}{|c|c|c|c|c|c|}
\hline \multicolumn{6}{|c|}{ Lesser curvature } \\
\hline 1-GA & 94.1 & (87.7 to 100.6$)$ & 92.0 & (86.9 to 97.0 ) & 0.625 \\
\hline 1-GEA & 2.0 & $(-1.8$ to 5.8$)$ & 1.8 & $(-0.7$ to 4.2$)$ & 0.939 \\
\hline r-GA & 27.5 & (15.2 to 39.7 ) & 22.3 & (14.6 to 30.0 ) & 0.477 \\
\hline r-GEA & 29.4 & (16.9 to 41.9 ) & 34.8 & (26.0 to 43.6 ) & 0.496 \\
\hline p-GA & 2.0 & $(-1.8$ to 5.8$)$ & 2.7 & ( -0.3 to 5.7$)$ & 0.784 \\
\hline Others & 7.8 & (0.5 to 15.2$)$ & 9.8 & (4.3 to 15.3 ) & 0.685 \\
\hline \multicolumn{6}{|c|}{ Greater curvature } \\
\hline 1-GA & 52.9 & (36.2 to 69.7 ) & 44.2 & (30.7 to 57.7 ) & 0.429 \\
\hline 1-GEA & 8.8 & $(-0.7$ to 18.4$)$ & 17.3 & (7.0 to 27.6 ) & 0.267 \\
\hline r-GA & 20.6 & (6.9 to 34.2 ) & 15.4 & (5.6 to 25.2 ) & 0.534 \\
\hline r-GEA & 79.4 & (65.8 to 93.0 ) & 86.5 & (45.9 to 63.3 ) & 0.871 \\
\hline p-GA & 0.0 & (0.0 to 0.0$)$ & 0.0 & (0.0 to 0.0$)$ & NA \\
\hline Others & 5.8 & $(-2.0$ to 13.8$)$ & 3.8 & ( -1.4 to 9.1 ) & 0.661 \\
\hline \multicolumn{6}{|c|}{ Anterior wall } \\
\hline 1-GA & 78.6 & (57.1 to 100.0 ) & 82.6 & (74.0 to 92.2 ) & 0.732 \\
\hline 1-GEA & 14.3 & $(-4.0$ to 32.6$)$ & 8.7 & (0.3 to 12.0 ) & 0.542 \\
\hline r-GA & 14.3 & $(-4.0$ to 32.6$)$ & 15.2 & (24.6 to 44.2 ) & 0.932 \\
\hline r-GEA & 78.6 & (57.1 to 100.0 ) & 73.9 & (71.2 to 87.9 ) & 0.724 \\
\hline $\mathrm{p}-\mathrm{GA}$ & 0.0 & (0.0 to 0.0$)$ & 0.0 & (0.0 to 0.0$)$ & NA \\
\hline Others & 0.0 & (0.0 to 0.0 ) & 0.0 & (0.1 to 8.5$)$ & NA \\
\hline \multicolumn{6}{|c|}{ Posterior wall } \\
\hline 1-GA & 84.6 & (70.7 to 98.5 ) & 83.1 & (56.9 to 76.4 ) & 0.858 \\
\hline 1-GEA & 3.8 & $(-3.5$ to 11.2$)$ & 6.2 & ( -1.1 to 3.2$)$ & 0.663 \\
\hline $\mathrm{r}-\mathrm{GA}$ & 11.5 & $(-0.7$ to 23.8$)$ & 9.2 & (24.6 to 44.2 ) & 0.739 \\
\hline r-GEA & 50.0 & (30.8 to 69.2 ) & 50.8 & (71.2 to 87.9 ) & 0.947 \\
\hline p-GA & 0.0 & $(0.0$ to 0.0$)$ & 0.0 & (0.0 to 0.0$)$ & NA \\
\hline Others & 3.8 & $(-3.5$ to 11.2$)$ & 4.6 & (0.1 to 8.5$)$ & 0.872 \\
\hline
\end{tabular}

Table 4 (continued)

$E R$ endoscopic resection, $l$-GA left gastric artery, $l$-GEA left gastroepiploic artery, $r$ - $G A$ right gastric artery, $r$-GEA right gastroepiploic artery, $p$-GA posterior gastric artery, $N A$ not applicable

ESD. It may be better not to perform SN biopsy for the perforated cases at least.

Although the dual-tracer method is currently the golden standard, a restriction on use of RI that required a nuclear medicine unit is a matter of concern especially in developing countries. The usefulness of non-radioactive tracer method such as near-infrared observation or magnetic tracer has been reported in recent years. The near-infrared observation using ICG is one of the most promising SN detection methods without RI. By developing the near-infrared imaging system, ICG near-infrared observation can aid in clearly visualizing SN and lymphatic route under laparoscope, making it easy to apply and compatible with laparoscopic surgery. We have also reported the optimal method of ICG near-infrared observation (dose concentration, injection volume, and timing), and its outcomes [22, 23]. In contrast, a practical application of a magnetic tracer completely different from RI is being utilized in case of other cancers. Magnetic tracer using superparamagnetic iron oxide has been used in clinical practice for breast cancer patients [24, 25], although there are no reports of it being used for gastric cancer. If a probe is developed for magnetic tracer that can be used in laparoscopic surgery, it may be used as a promising alternative to RI. These tracers have the potential to become an alternative to dual tracers in the future. Further investigations about non-radioactive tracers are needed to spread the practicability of SNNS for gastric cancer to a wide extent.

Although no change in the lymphatic basin was observed from before to after ER, non-SN metastasis within the SN basin was observed in one of the nine patients with lymph node metastasis in this study. This $11 \%$ false-negative rate should not be ignored. Few reports have described detailed examinations of lymph flow after ER. We studied lymphatic flow after ER in a pig model [26]. The evaluation of lymph flow on ICG imaging before and 4 weeks after ESD showed no change in $10(83.3 \%)$ of the 12 cases. However, the preESD lymph flow partially disappeared, and new lymph flow appeared in the lesser curvature side of the middle and lower stomach. Although lymph flow does not generally change with ER, the effect of ER may vary among sites in the long- and short-axis directions. The SN basin reportedly has $\geq 2$ complex structures in the middle and lower parts of the stomach as compared with the upper part of the stomach [27]. In the false-negative case, the lymph flow might have been changed by ER. Furthermore, it might have been caused by an SN detection procedure because SN mapping was performed using the only dye method at laparotomy in that case. In the additional surgery for post-ER gastric 
cancer, whose lymph node metastasis rate is not so high, SNs should be reliably identified to minimize the occurrence of false negatives. In addition, the curability can be ensured by resecting the SNs and SN basin. At least now, validation by a prospective study using the dual-tracer method for postER gastric cancer is necessary.

This study has some limitations. The SN detection method was not uniform, as single or dual tracers, and RI or/and dye were used. The investigators from the participating hospitals in this retrospective study conducted a multicenter prospective trial of SN navigation surgery for gastric cancer; therefore, the detailed procedures for $\mathrm{SN}$ detection have been unified.

In summary, our findings clarify the feasibility of SN mapping based on the SN basin concept in patients with gastric cancer who previously underwent ER. The multicenter prospective trial of laparoscopic sentinel basin dissection after ESD for early gastric cancer (SENORITA 2 trial [28]) is ongoing in Korea. We are also planning to start a prospective trial using the dual-tracer method to validate the SN concept for post-ER gastric cancer.

Funding No funding.

\section{Compliance with ethical standards}

Conflict of interest The authors declare no conflict of interest.

Ethical approval All procedures performed in studies involving human participants were in accordance with the ethical standards of the institutional research committee and with the 1964 Helsinki declaration and its later amendments.

Informed consent Informed consent was obtained from all individual participants included in the study.

Open Access This article is licensed under a Creative Commons Attribution 4.0 International License, which permits use, sharing, adaptation, distribution and reproduction in any medium or format, as long as you give appropriate credit to the original author(s) and the source, provide a link to the Creative Commons licence, and indicate if changes were made. The images or other third party material in this article are included in the article's Creative Commons licence, unless indicated otherwise in a credit line to the material. If material is not included in the article's Creative Commons licence and your intended use is not permitted by statutory regulation or exceeds the permitted use, you will need to obtain permission directly from the copyright holder. To view a copy of this licence, visit http://creativecommons.org/licenses/by/4.0/.

\section{References}

1. Information Service NCC, Japan. Annual Report of HospitalBased Cancer Registries. https://jhcr-cs.ganjoho.jp/hbcrtables/ search-result.aspx? UnitType=2. Accessed 1 Oct 2019.

2. Tada M, Murakami A, Karita M, Yanai H, Okita K. Endoscopic resection of early gastric cancer. Endoscopy. 1993;25:445-50.
3. Ono H, Kondo H, Gotoda T, Shirao K, Yamaguchi H, Saito D, et al. Endoscopic mucosal resection for treatment of early gastric cancer. Gut. 2001;48:225-9.

4. Hirao M, Masuda K, Asanuma T, Naka H, Noda K, Matsuura $\mathrm{K}$, et al. Endoscopic resection of early gastric cancer and other tumors with local injection of hypertonic saline-epinephrine. Gastrointest Endosc. 1988;34:264-9.

5. Japanese Gastric Cancer Association. Japanese gastric cancer treatment guidelines 2018 (ver.5). Kanehara; 2018.

6. Hasuike N, Ono H, Boku N, Mizusawa J, Takizawa K, Fukuda H, et al. A non-randomized confirmatory trial of an expanded indication for endoscopic submucosal dissection for intestinal-type gastric cancer (cT1a): the Japan Clinical Oncology Group study (JCOG0607). Gastric Cancer. 2018;21:114-23.

7. Wong SL, Faries MB, Kennedy EB, Agarwala SS, Akhurst TJ, Ariyan C, et al. Sentinel lymph node biopsy and management of regional lymph nodes in melanoma: American Society of Clinical Oncology and Society of Surgical Oncology Clinical Practice Guideline Update. J Clin Oncol. 2018;36:399-413.

8. Lyman GH, Somerfield MR, Bosserman LD, Perkins CL, Weaver DL, Giuliano AE. Sentinel lymph node biopsy for patients with early-stage breast cancer: American Society of Clinical Oncology Clinical Practice Guideline Update. J Clin Oncol. 2017;35:561-4.

9. Kataoka F, Susumu N, Yamagami W, Kuwahata M, Takigawa A, Nomura $\mathrm{H}$, et al. The importance of para-aortic lymph nodes in sentinel lymph node mapping for endometrial cancer by using hysteroscopic radio-isotope tracer injection combined with subserosal dye injection: Prospective study. Gynecol Oncol. 2016;140:400-4.

10. Schilling C, Stoeckli SJ, Vigili MG, de Bree R, Lai SY, Alvarez $\mathrm{J}$, et al. Surgical consensus guidelines on sentinel node biopsy (SNB) in patients with oral cancer. Head Neck. 2019;41:2655-64.

11. Takeuchi H, Fujii H, Ando N, Ozawa S, Saikawa Y, Suda K, et al. Validation study of radio-guided sentinel lymph node navigation in esophageal cancer. Ann Surg. 2009;249:757-63.

12. Takeuchi H, Kitagawa Y. Sentinel node navigation surgery in esophageal cancer. Ann Gastroenterol Surg. 2019;3:7-13.

13. Miwa K, Kinami S, Taniguchi K, Fushida S, Fujimura T, Nonomura A. Mapping sentinel nodes in patients with early-stage gastric carcinoma. Br J Surg. 2003;90:178-82.

14. Kitagawa Y, Takeuchi H, Takagi Y, Natsugoe S, Terashima $\mathrm{M}$, Murakami N, et al. Sentinel node mapping for gastric cancer: a prospective multicenter trial in Japan. J Clin Oncol. 2013;31:3704-10.

15. Arigami T, Uenosono $Y$, Yanagita S, Matsushita D, Arima H, Hirata M, et al. Feasibility of sentinel node navigation surgery after noncurative endoscopic resection for early gastric cancer. $\mathbf{J}$ Gastroenterol Hepatol. 2013;28:1343-7.

16. Mayanagi S, Takeuchi H, Kamiya S, Niihara M, Nakamura R, Takahashi T, et al. Suitability of sentinel node mapping as an index of metastasis in early gastric cancer following endoscopic resection. Ann Surg Oncol. 2014;21:2987-93.

17. Japanese Gastric Cancer Association. Japanese Classification of Gastric Carcinoma (The 15th Edition). Kanehara; 2017.

18. Kinami S, Fujimura T, Ojima E, Fushida S, Ojima T, Funaki H, et al. PTD classification: proposal for a new classification of gastric cancer location based on physiological lymphatic flow. Int $\mathrm{J}$ Clin Oncol. 2008;13:320-9.

19. Takeuchi H, Kitagawa Y. New sentinel node mapping technologies for early gastric cancer. Ann Surg Oncol. 2013;20:522-32.

20. Takeuchi H, Goto O, Yahagi N, Kitagawa Y. Function-preserving gastrectomy based on the sentinel node concept in early gastric cancer. Gastric Cancer. 2017;20:53-9.

21. Wang Z, Dong ZY, Chen JQ, Liu JL. Diagnostic value of sentinel lymph node biopsy in gastric cancer: a meta-analysis. Ann Surg Oncol. 2012;19:1541-50. 
22. Yano K, Nimura H, Mitsumori N, Takahashi N, Kashiwagi H, Yanaga $\mathrm{K}$. The efficiency of micrometastasis by sentinel node navigation surgery using indocyanine green and infrared ray laparoscopy system for gastric cancer. Gastric Cancer. 2012;15:287-91.

23. Kinami S, Oonishi T, Fujita J, Tomita Y, Funaki H, Fujita H, et al. Optimal settings and accuracy of indocyanine green fluorescence imaging for sentinel node biopsy in early gastric cancer. Oncol Lett. 2016;11:4055-62.

24. Douek M, Klaase J, Monypenny I, Kothari A, Zechmeister K, Brown D, et al. Sentinel node biopsy using a magnetic tracer versus standard technique: the SentiMAG Multicentre Trial. Ann Surg Oncol. 2014;21:1237-45.

25. Zada A, Peek MC, Ahmed M, Anninga B, Baker R, Kusakabe M, et al. Meta-analysis of sentinel lymph node biopsy in breast cancer using the magnetic technique. Br J Surg. 2016;103:1409-19.

26. Nohara K, Goto O, Takeuchi H, Sasaki M, Maehata T, Yahagi $\mathrm{N}$, et al. Gastric lymphatic flows may change before and after endoscopic submucosal dissection: in vivo porcine survival models. Gastric Cancer. 2019;22:723-30.

27. Aoyama J, Kawakubo H, Goto O, Nakahara T, Mayanagi S, Fukuda K, et al. Potential for local resection with sentinel node basin dissection for early gastric cancer based on the distribution of primary sites. Gastric Cancer. 2019;22:386-91.

28. Eom BW, Yoon HM, Min JS, Cho I, Park JH, Jung MR, et al. Prospective multicenter feasibility study of laparoscopic sentinel basin dissection after endoscopic submucosal dissection for early gastric cancer: SENORITA 2 trial protocol. J Gastric Cancer. 2019;19:157-64.

Publisher's Note Springer Nature remains neutral with regard to jurisdictional claims in published maps and institutional affiliations. 